ARTICLE

\title{
NIR-excitable heterostructured upconversion perovskite nanodots with improved stability
}

\author{
Longfei Ruan ${ }^{1} \&$ Yong Zhang (10 ${ }^{1,2 凶}$
}

There is a great need to develop heterostructured nanocrystals which combine two or more different materials into single nanoparticles with combined advantages. Lead halide perovskite quantum dots (QDs) have attracted much attention due to their excellent optical properties but their biological applications have not been much explored due to their poor stability and short penetration depth of the UV excitation light in tissues. Combining perovskite QDs with upconversion nanoparticles (UCNP) to form hybrid nanocrystals that are stable, NIR excitable and emission tunable is important, however, this is challenging because hexagonal phase UCNP can not be epitaxially grown on cubic phase perovskite QDs directly or vice versa. In this work, one-pot synthesis of perovskite-UCNP hybrid nanocrystals consisting of cubic phase perovskite QDs and hexagonal phase UCNP is reported, to form a watermelon-like heterostructure using cubic phase UCNP as an intermediate transition phase. The nanocrystals are NIR-excitable with much improved stability.

\footnotetext{
${ }^{1}$ Department of Biomedical Engineering, Faculty of Engineering, National University of Singapore, Singapore 117583, Singapore. ${ }^{2}$ NUS Graduate School for Integrative Sciences and Engineering, National University of Singapore, Singapore 117456, Singapore. ${ }^{凶}$ email: biezy@nus.edu.sg
} 
T here is increasing interest in developing heterostructured nanocrystals that combine two or more different materials into single nanoparticles with combined advantages. For example, heterostructured quantum dots (QDs) such as InP/ZnS, $\mathrm{CdSe} / \mathrm{CdS} / \mathrm{ZnS}, \mathrm{Si} / \mathrm{CdS}, \mathrm{PbSe} / \mathrm{PbS}$, and $\mathrm{CdSe} / \mathrm{CdTe}$ QDs have been synthesized and have exhibited significantly improved optical and electrical properties as compared to their individual constituents $\mathrm{s}^{1,2}$. QDs are semiconductor nanoparticles whose excitons are limited to the Bohr radius in three-dimensional space, showing the quantum confinement effect ${ }^{3}$. Traditional quantum dots are made of compounds of the IV, II-VI, IV-VI, III-V, and I-III-VI groups, such as $\mathrm{Si}$, CdTe, CdSe, $\mathrm{ZnO}, \mathrm{PbS}$, InP, $\mathrm{CuInS}_{2}$ QDs, etc ${ }^{4,5}$. In recent years, lead halide perovskite QDs have attracted much attention due to their excellent optical properties such as high photoluminescence quantum yield (PLQY) up to $100 \%^{6-8}$, large UV absorption cross section" tunable emission over the entire visible spectrum ${ }^{10,11}$, long carrier diffusion length, and high carrier mobility ${ }^{12}$, which make them suitable for use in high-performance solar cells, light-emitting diodes (LEDs), lasers, and photodetectors ${ }^{10-14}$. However, perovskites have poor stability which limits their applications. Furthermore, their use in biological and medical applications is also very limited due to the low penetration depth of UV light in biological tissues. As compared to perovskite QDs, lanthanidedoped upconversion nanocrystals (UCNP) such as $\mathrm{NaYF}_{4}: \mathrm{Yb}$, Tm have good stability and much higher multi-photon absorption efficiency under NIR excitation using low-cost continuous-wave (CW) lasers ${ }^{15,16}$. UCNP have been used in deep tissue fluorescence imaging and phototherapy due to deep penetration of NIR light in biological tissues ${ }^{17-20}$. However, UCNP have fluorescence emissions at fixed wavelengths only and their emission colors are not tunable and as such their use in multiplexed bioimaging or bioassays is limited. Combining perovskite QDs with UCNP to form hybrid nanocrystals with a heterostructure that are stable, NIR excitable and emission tunable may address the abovementioned issues. Some studies have been performed to synthesize hybrid perovskite nanocrystals with semiconductor quantum dots with small crystal phase-mismatch such as $\mathrm{CsPbBr}_{3}-\mathrm{CdS}^{21}$, $\mathrm{CsPbI}-\mathrm{PbS}_{3}^{22}$, and $\mathrm{CsPbBr}_{3}-\mathrm{TiO}_{2}{ }^{23}$ and bulk materials, such as $\mathrm{MAPbI}_{3}-\mathrm{PbS}^{24}$ and $\mathrm{CsPbX}_{3}-\mathrm{PbS}(\mathrm{X}=\mathrm{Cl}, \mathrm{Br} \text {, and })^{25}$. Previous attempts have been made to synthesize UCNP-perovskite nanohybrids. The synthesis of $\mathrm{NaYF}_{4}: \mathrm{Yb}, \mathrm{Tm} @ \mathrm{CH}_{3} \mathrm{NH}_{3} \mathrm{PbBr}_{3}$ nanohybrids via an innovative strategy consisting of using cucurbituril to anchor the perovskite nanoparticles firmly and closely to the upconversion nanoparticles has been previously achieved ${ }^{26}$. This is a typical A + B synthesis strategy. Material A and B were first synthesized, and an intermediate molecule cucurbituril was used to link the two materials to obtain $\mathrm{AB}$ composite material. The composite of perovskite NWs and UCNPs was synthesized at room temperature using PVP as a template ${ }^{27}$. First, the PVPmodified UCNPs were synthesized, and they were mixed with $\mathrm{Pb}$ $(\mathrm{OA})_{2}$, which was a perovskite NWs precursor. 1-cysteine was added and dispersed in isopropanol solution, and $\mathrm{CH}_{3} \mathrm{NH}_{3} \mathrm{Br}$, another precursor of NWs, was added to obtain an $\mathrm{AB}$ composite. It is typical to synthesize material A first and then rely on the template method to get the composite material of $\mathrm{AB}$ during the synthesis process of material $B$. They all rely on the action of chemical bonds to connect the two synthetic materials, while we have creatively introduced the intermediate synthesis of crystal phase by controlling the crystal growth, and use the phasetransition characteristics to obtain heterojunction materials with excellent optical properties. However, it remains a challenge to synthesize perovskite/UCNP heterostructured nanocrystals due to the structural difference between cubic-phase perovskite QDs and hexagonal-phase UCNP and lack of a good understanding of the growth/formation mechanism. Going beyond perovskites and
UCNP, this has posed a challenge in synthesizing heterostructured nanocrystals consisting of two or more different crystal phases with structural and lattice mismatch and a generic strategy must be developed.

In general, some stringent requirements must be met for making heterostructured nanocrystals: (I) crystal structure matching. Cubic-phase $\mathrm{CsPbBr}_{3}$ crystals can grow together with cubic-phase $\mathrm{CdS}$ or $\mathrm{PbS}$ crystals $^{21,25}$; (II) lattice parameter matching. $\mathrm{MAPbI}_{3}-\mathrm{PbS}$ lattice mismatch was as small as $4.9 \%{ }^{24}$; (III) similar reaction temperature and condition ${ }^{21}$. There are two strategies for synthesizing A-B hybrid nanocrystals with two different crystals A and B: (I) monodispersed A nanocrystals are synthesized first and then $B$ is epitaxially grown on the surface of A nanocrystals to form a core-shell structure. (II) A and B are synthesized in the same solution simultaneously to produce hybrid nanocrystals with $\mathrm{A}$ embedded in B or B embedded in A. Both strategies require $\mathrm{A}$ and $\mathrm{B}$ to have the same crystal structure and closely matched structural and lattice parameters. For synthesizing perovskite-UCNP hybrid nanocrystals, in this work $\mathrm{CsPbBr}_{3}-\mathrm{NaYF}_{4}: \mathrm{Yb}, \mathrm{Tm}$, strategy II is adopted. Multiple $\mathrm{CsPbBr} 3$ perovskite QDs are embedded in the $\mathrm{NaYF}_{4}: \mathrm{Yb}, \mathrm{Tm}$ UCNP to ensure there is sufficient absorption of NIR excitation light and efficient energy transfer from the UCNP to perovskite QDs. On the other side, it has been widely reported that $\mathrm{CsPbBr}_{3}$ perovskite QDs have very poor stability in water ${ }^{23,28}$. Embedding them in the UCNP will help prevent them from dissolving in water. The challenge to overcome is how to embed cubic-phase $\mathrm{CsPbBr}_{3}$ QDs in hexagonal-phase $\mathrm{NaYF}_{4}: \mathrm{Yb}, \mathrm{Tm}$ UCNP to form hybrid nanocrystals in the same synthetic solution by one-pot synthesis. It is noted that the lattice mismatch between cubicphase $\mathrm{CsPbBr}_{3}$ QDs and $\mathrm{NaYF}_{4}: \mathrm{Yb}, \mathrm{Tm}$ UCNP is small, $5.9 \%$ only. Our hypothesis is those hybrid nanocrystals consisting of cubic-phase $\mathrm{CsPbBr}_{3}$ QDs and cubic-phase $\mathrm{NaYF}_{4}: \mathrm{Yb}, \mathrm{Tm}$ UCNP can be first prepared in one-pot based on co-precipitation method due to small crystal structure mismatch and similarity in synthetic conditions. Phase transition of the UCNP from cubic phase to hexagonal phase is then induced by heating to a higher temperature, resulting in the formation of hybrid nanocrystals with cubic phase $\mathrm{Cs} \mathrm{PbBr}_{3}$ QDs embedded in hexagonal-phase $\mathrm{NaYF}_{4}$ : $\mathrm{Yb}, \mathrm{Tm} \mathrm{UCNP}^{29}$.

In this work, we have demonstrated the successful synthesis of monodispersed and oval-shaped watermelon-like hybrid nanocrystals consisting of small cubic-phase $\mathrm{CsPbBr}_{3}$ QDs (watermelon seeds) embedded in hexagonal-phase $\mathrm{NaYF}_{4}: \mathrm{Yb}, \mathrm{Tm}$ UCNP (watermelon pulp) with a thin $\mathrm{NaYF}_{4}: \mathrm{Yb}, \mathrm{Tm}$ shell (watermelon skin). The hybrid nanocrystals emit characteristic green fluorescence of the $\mathrm{CsPbr}_{3}$ QDs upon UV excitation and UV-blue fluorescence of the $\mathrm{NaYF}_{4}: \mathrm{Yb}$, Tm UCNP upon NIR excitation, demonstrating the co-existence of both $\mathrm{CsPbBr}_{3}$ phase and $\mathrm{NaYF}_{4}: \mathrm{Yb}, \mathrm{Tm}$ phase in the same structure, and green fluorescence upon NIR excitation when the $\mathrm{NaYF}_{4}: \mathrm{Yb}, \mathrm{Tm}$ phase absorbs NIR light and transfers the energy to the $\mathrm{Cs} \mathrm{PbBr}_{3}$ phase. This has opened a new way of synthesizing heterostructured nanocrystals with two distinctly different crystal phases via an intermediate transition phase and the strategy could be applied to many other materials.

\section{Results}

Synthesis of $\mathrm{CsPbBr}_{3}$ QDs and $\mathrm{NaYF}_{4}: \mathrm{Yb}$, Tm UCNP. CsPbBr QDs with regular cubic shape were first synthesized based on Kovalenko's method ${ }^{30}$. The size of the $\mathrm{CsPbBr}_{3}$ QDs was $12.6 \mathrm{~nm}$, and the diffraction peaks at $2 \theta=15.2,21.6,26.530 .6,34.4,37.8$, $43.9,46.7,49.4,54.5$, and $59.3^{\circ}$ correspond to diffractions from the $\{100\},\{110\},\{111\},\{200\},\{210\},\{211\},\{220\},\{300\}$, $\{310\},\{222\}$, and $\{321\}$ planes of the cubic-phase $\mathrm{CsPbBr}_{3}$ 
(PDF\# 00-054-0752) (Supplementary Figs. 1 and 2). To analyze the optical properties, the UV-vis absorption spectra, and the PL emission and excitation spectra (Supplementary Fig. 3) was obtained from the colloidal solution of the $\mathrm{CsPbBr}_{3}$ nanocrystals. The PL emission spectrum showed a peak position at $515 \mathrm{~nm}$ and showed a strong green fluorescence under $365 \mathrm{~nm}$ excitation (Supplementary Fig. 3A). The absorption onset of $\mathrm{CsPbBr}_{3}$ nanocrystals was around $510 \mathrm{~nm}$ (Supplementary Fig. 3B). The time-resolved PL decay of $\mathrm{Cs}_{\mathrm{PbBr}}$ showed average PL decay lifetimes was $18.4 \mathrm{~ns}$ (Supplementary Fig. 3C and Supplementary Table 1). $\mathrm{NaYF}_{4}: 30 \% \mathrm{Yb}, 0.5 \% \mathrm{Tm}$ nanocrystals were synthesized by the high-temperature co-precipitation method ${ }^{31}$. When the temperature reached $300{ }^{\circ} \mathrm{C}, \mathrm{NaYF}_{4}: 30 \% \mathrm{Yb}$ and $0.5 \% \mathrm{Tm}$ nanocrystals with a size of about $5 \mathrm{~nm}$ were synthesized, and they emitted a weak fluorescence under $980 \mathrm{~nm}$ excitation (Supplementary Fig. 5). At $300{ }^{\circ} \mathrm{C}$ for $60 \mathrm{~min}$, uniform $\mathrm{NaYF}_{4}: 30 \%$ $\mathrm{Yb}, 0.5 \% \mathrm{Tm}$ nanocrystals with a size of $32.5 \mathrm{~nm}$ were synthesized, and they emitted a strong blue fluorescence under $980 \mathrm{~nm}$ excitation (Supplementary Fig. 6). According to the XRD results (Supplementary Fig. 7), the diffraction peaks at $2 \theta=17.2,30.1$, $30.8,34.6,39.6,43.5,46.5,52.1,53.1,53.7$, and $55.2^{\circ}$ correspond to diffractions from the $\{100\},\{110\},\{101\},\{200\},\{111\},\{201\}$, $\{210\},\{002\},\{300\},\{211\}$, and $\{102\}$ planes of the hexagonalphase $\mathrm{NaYF}_{4}$ (JCPDS: 00-016-0334).

Synthesis of heterostructured nanocrystals. As shown in Fig. 1a, cubic-phase $\mathrm{NaYF}_{4}: \mathrm{Yb}, \mathrm{Tm}$ UCNP can be epitaxially grown on the surface of cubic-phase $\mathrm{CsPbBr}$ Q QDs due to the similarity in the crystal structure and lattice. When the temperature is increased, UCNP is converted from cubic to hexagonal phase, while cubicphase $\mathrm{CsPbBr}_{3}$ QDs remain unchanged so hexagonal-phase
UCNP is formed on the surface of cubic-phase $\mathrm{CsPbBr}_{3}$ QDs. $\mathrm{Cs}_{\mathrm{PbBr}}-\mathrm{NaYF}_{4}: \mathrm{Yb}, \mathrm{Tm}$ hybrid nanocrystals were synthesized using a high-temperature co-precipitation method. Their formation and crystal structures were studied. $\mathrm{CsPBBr}_{3}$ QDs with regular cubic shape were first synthesized based on Kovalenko's method (Supplementary Fig. 1) ${ }^{11}$, and then added to the precursor solution for UCNP synthesis which consists of various lanthanide ions such as $\mathrm{Y}^{3+}, \mathrm{Yb}^{3+}$, and $\mathrm{Tm}^{3+}$ and surfactants, such as oleic acid (OA) and octadecylene (ODE). As shown in Fig. 1b-e, heterostructured nanocrystals were formed with the $\mathrm{CsPbBr}_{3}$ QDs embedded in the $\mathrm{NaYF}_{4}: \mathrm{Yb}, \mathrm{Tm}$ UCNP, to form a structure similar to that of watermelon with multiple seeds. The average size of the nanocrystals was $\sim 37 \mathrm{~nm}$, and the outer shell was $~ 3.7-\mathrm{nm}$ thick (Fig. 1c). $\mathrm{CsPbBr}_{3}$ QDs were found to be in the middle region of the nanocrystals with distinct crystal boundary formed between the $\mathrm{CsPBr}_{3}$ QDs and UCNP from the bright- and dark-field TEM images. The heterostructure interface can be clearly seen from the HRTEM diagram (Supplementary Fig. 8), and the area segmented by the arc presents obvious light and dark patterns. Above the arc is the cubic-phase $\mathrm{CsPbBr}$ crystals and below the arc is the hexagonal-phase $\mathrm{NaYF}_{4}: \mathrm{Yb}, \mathrm{Tm}$ crystals. The cubic-phase $\mathrm{NaYF}_{4}: \mathrm{Yb}, \mathrm{Tm}$ is a metastable crystalline phase, which led to the formation of irregular small cubic-phase $\mathrm{Cs} \mathrm{PbBr}_{3}$ crystals within the heterogeneous junction, thus making the interface of heterogeneous junction irregular. From HRTEM, STEM, and elemental imaging results (Supplementary Fig. 9), it can be clearly seen that the perovskites in the heterostructured nanocrystals were small irregular particles with a size of 6-12 nm. At $250^{\circ} \mathrm{C}$, the heterostructured nanocrystals were composed of a cubic-phase UCNPs and cubic-phase perovskites. The cubicphase UCNPs has a high-temperature metastable crystalline phase, which led to the irregular growth of perovskites in the
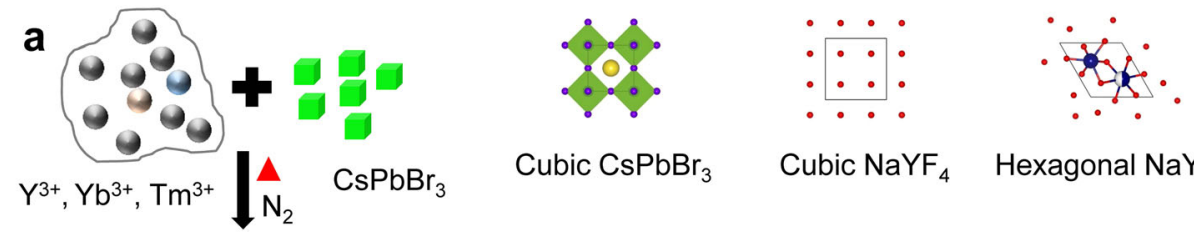

Cubic $\mathrm{CsPbBr}_{3} \quad \mathrm{Cubic} \mathrm{NaYF}_{4} \quad$ Hexagonal $\mathrm{NaYF}_{4}$
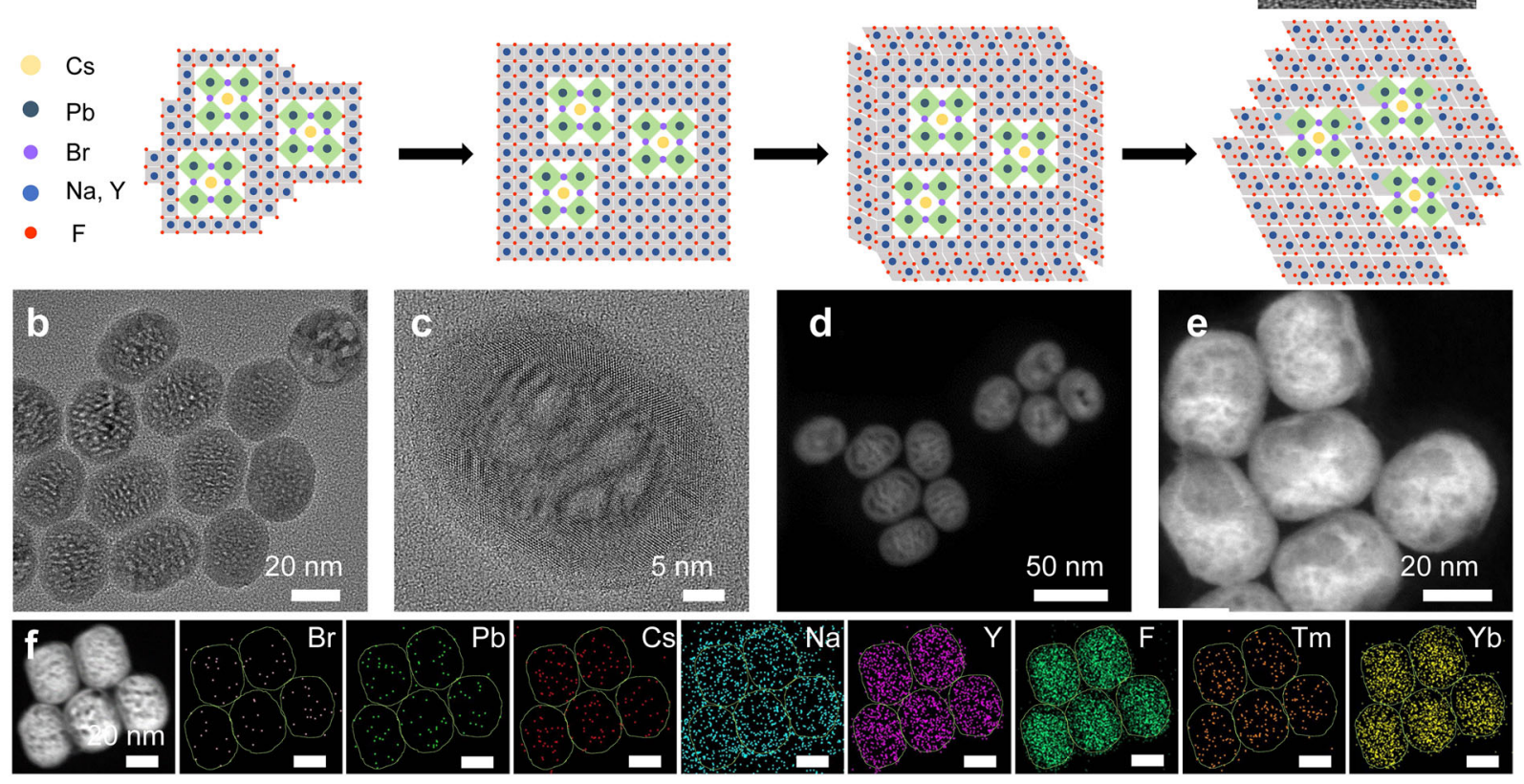

Fig. 1 Synthesis of $\mathbf{C s P b B r}_{3}-\mathrm{NaYF}_{\mathbf{4}}: \mathbf{Y b}, \mathbf{T m}$ hybrid nanocrystals. a Schematic showing the formation of heterostructured $\mathrm{CsPbBr}_{3}-\mathrm{NaYF}_{4}: \mathrm{Yb}_{1}, \mathrm{Tm}_{\mathrm{m}}$ nanocrystals, b, c TEM and d, e STEM images of heterostructured $\mathrm{CsPbBr}_{3}-\mathrm{NaYF}_{4}: \mathrm{Yb}, \mathrm{Tm}$ nanocrystals. $\mathbf{f}$ Elemental mapping of heterostructured $\mathrm{CsPbBr}_{3}-\mathrm{NaYF}_{4}: \mathrm{Yb}, \mathrm{Tm}$ nanocrystals. Scale bars in $\mathbf{f}, 20 \mathrm{~nm}$. 
heterojunction. Subsequently, under the effects of thermodynamics $\left(250-300^{\circ} \mathrm{C}\right)$, the cubic-phase UCNP transited to the hexagonal phase. At this time, the epitaxial growth was mainly due to the hexagonal-phase UCNP, and most of the perovskite stopped growing due to the mismatch of crystal phases. As shown in Fig. 1f, eight elements including $\mathrm{Br}, \mathrm{Pb}, \mathrm{Cs}, \mathrm{Na}, \mathrm{Y}, \mathrm{F}, \mathrm{Tm}$, and $\mathrm{Yb}$ were distributed in the nanocrystal structure (Supplementary Fig. 10). The elemental mapping images showed that $\mathrm{Na}, \mathrm{Y}, \mathrm{F}$, $\mathrm{Tm}$, and $\mathrm{Yb}$ ions which constitute the $\mathrm{NaYF}_{4}: \mathrm{Yb}, \mathrm{Tm}$ UCNP were uniformly distributed throughout the hybrid nanocrystals, while $\mathrm{Br}, \mathrm{Pb}$, and $\mathrm{Cs}$ ions which make up $\mathrm{Cs}_{\mathrm{PbBr}}$ QDs were located in the middle part. This could also be seen from the images of single-particle element imaging (Supplementary Fig. 11), supporting that the hybrid nanocrystals were formed with the $\mathrm{CsPbBr} 3$ QDs embedded in the $\mathrm{NaYF}_{4}: \mathrm{Yb}$,Tm UCNP. According to the XPS results, the concentration ratio of $\mathrm{CsPbBr}_{3}$ and $\mathrm{NaYF}_{4}$ : $\mathrm{Yb}, \mathrm{Tm}$ in the heterostructured nanocrystals was 1:59. (Supplementary Table 2).

Nanocrystal heterostructure formation during heat treatment. The formation of the $\mathrm{CsPbBr}_{3}-\mathrm{NaYF}_{4}: \mathrm{Yb}, \mathrm{Tm}$ hybrid nanocrystals was studied by TEM measurement of the samples collected at different temperatures during the heat-treatment process. From the literature, it was reported that cubic-phase $\mathrm{CsPbBr}$ crystals (5.83 $\AA$ ) and cubic-phase $\mathrm{NaYF}_{4}$ crystals (5.47 $\AA$ ) have a small lattice mismatch of $\sim 5.9 \%$, suggesting that theoretically it is possible to grow cubic phase $\mathrm{CsPbBr}_{3}$ crystals on cubic-phase $\mathrm{NaYF}_{4}$ crystals epitaxially or vice versa ${ }^{32-34}$. In this study, premade cubic-phase $\mathrm{CsPbr}_{3}$ QDs were added to the precursor solution to synthesize $\mathrm{NaYF}_{4}: \mathrm{Yb}, \mathrm{Tm} \mathrm{UCNP}$, so it is a high probability that $\mathrm{NaYF}_{4}: \mathrm{Yb}, \mathrm{Tm}$ crystals were grown on the surface of $\mathrm{CsPbBr}_{3}$ QDs, evidenced from the dark spots formed on the surface of the cubic-shape nanocrystals at $150{ }^{\circ} \mathrm{C}$ and $200^{\circ} \mathrm{C}$, as shown in Fig. 2a, b. This is similar to cubic-phase $\mathrm{CsPbX}_{3}-\mathrm{PbS}$ hybrid nanocrystals formed under a similar condition ${ }^{25}$. The temperature was subsequently increased to $250^{\circ} \mathrm{C}$, resulting in much smaller nanocrystals with a size of $\sim 12 \mathrm{~nm}$ (Fig. 2c). Besides poor chemical stability in water, poor thermostability of $\mathrm{CsPbBr}_{3}$ QDs has also been well reported ${ }^{35,36}$. High temperature may cause the oxidation and hydration and eventually the decomposition of $\mathrm{CsPbBr}$ Q QD. At $250{ }^{\circ} \mathrm{C}$, the size of the nanocrystals was apparently much smaller as compared to a lower temperature, suggesting that $\mathrm{Cs} \mathrm{PbBr}_{3}$ QDs started to decompose partially. This is usually considered a problem for perovskite QDs; however, in this study, the smaller size of perovskite QDs caused by partial decomposition makes it possible to synthesize small perovskite-UCNP hybrid nanocrystals. On the other side, the cubic phase is dominant in the $\mathrm{NaYF}_{4}$ nanocrystals formed at $250{ }^{\circ} \mathrm{C}$, as previously reported $29,37,38$. The small hybrid nanocrystals served as the seeds for further growth of the $\mathrm{NaYF}_{4}: \mathrm{Yb}$, Tm UCNP. The average size of the nanocrystals increased to 30.6 $\mathrm{nm}$ when the temperature reached $300{ }^{\circ} \mathrm{C}$ (Fig. 2d). With the extension of the insulation time to 30 and $60 \mathrm{~min}$, the size continued to increase to $34.5 \mathrm{~nm}$ and $37.1 \mathrm{~nm}$, respectively (Fig. 2e, f). Their morphology changed from square or hexagonal to ellipsoidal shape. In addition, multiple cores were clearly observed in the middle region of the perovskite-UCNP hybrid nanocrystals during the thermal insulation process (Supplementary Fig. 12), which was consistent with the previous elemental mapping results.

Luminescence emission profile. The fluorescence emission of nanocrystals is dependent on the crystal structure and phases. Fluorescence emission spectra of the perovskite-UCNP hybrid nanocrystals collected at different temperatures were measured under excitation at $980 \mathrm{~nm}$ and $365 \mathrm{~nm}$, respectively, and used to study the crystal phase formation and transition during the synthesis of the hybrid nanocrystals. As shown in Fig. 3a, the hybrid nanocrystals had three different states of luminescence: it emitted blue and cyan fluorescence under $980 \mathrm{~nm}$ excitation and green fluorescence under $365 \mathrm{~nm}$ excitation. When the temperature was increased from $150^{\circ} \mathrm{C}$ to $250^{\circ} \mathrm{C}$, upconversion luminescence was weak and there was no characteristic green fluorescence emission of $\mathrm{CsPbBr}_{3}$ QDs at $515 \mathrm{~nm}$ under $980 \mathrm{~nm}$ excitation, indicating that there is no energy transfer from the $\mathrm{NaYF}_{4}: \mathrm{Yb}, \mathrm{Tm} \mathrm{UCNP}$ to $\mathrm{CsPbr}_{3}$ QDs due to the low luminescence efficiency of cubic-phase $\mathrm{NaYF}_{4}: \mathrm{Yb}, \mathrm{Tm} \mathrm{UCNP}$ formed at low temperature ${ }^{38,39}$. The intensity of the green fluorescence of $\mathrm{CsPbBr}_{3}$ QDs under $365 \mathrm{~nm}$ excitation
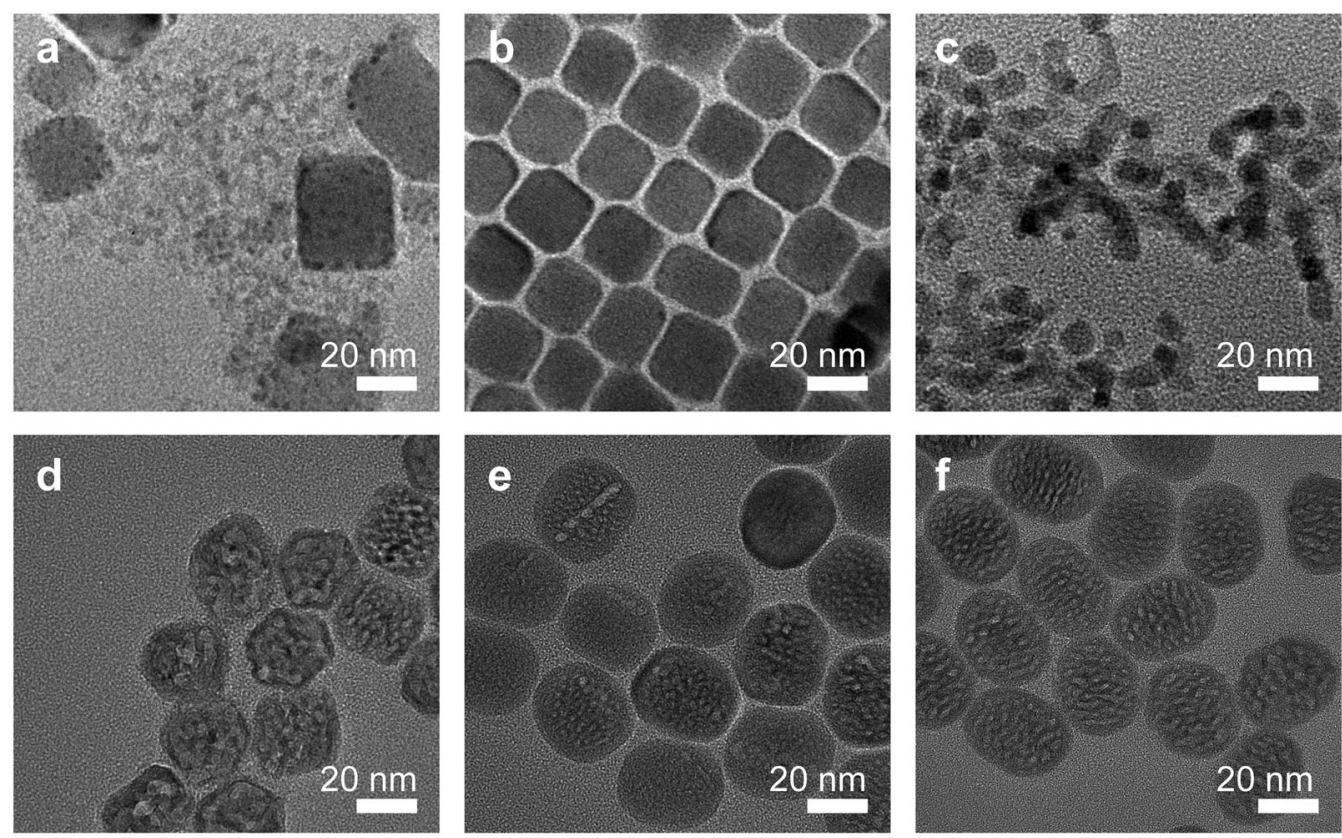

Fig. 2 Nanocrystal heterostructure formation during heat treatment. TEM images of heterostructured $\mathrm{CsPbBr}_{3}-\mathrm{NaYF}_{4}: \mathrm{Yb}_{1} \mathrm{Tm}_{\mathrm{m}}$ nanocrystals collected during the synthesis at different temperatures. a $150^{\circ} \mathrm{C}, \mathbf{b} 200^{\circ} \mathrm{C}, \mathbf{c} 250^{\circ} \mathrm{C}, \mathbf{d ~} 300^{\circ} \mathrm{C}-0 \mathrm{~min}, \mathbf{e ~} 300^{\circ} \mathrm{C}-30 \mathrm{~min}, \mathbf{f} 300^{\circ} \mathrm{C}-60 \mathrm{~min}$. 
a
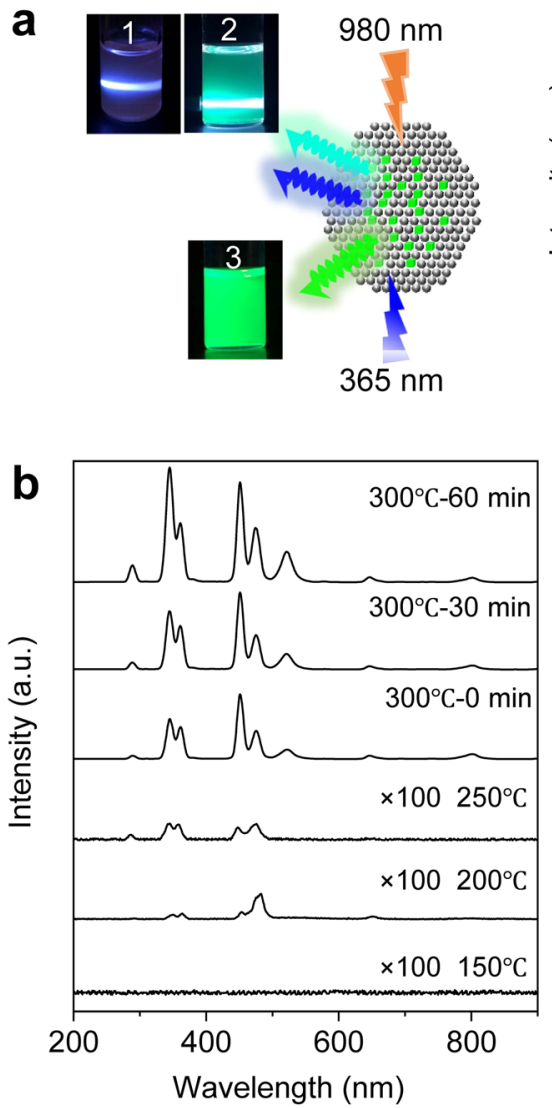
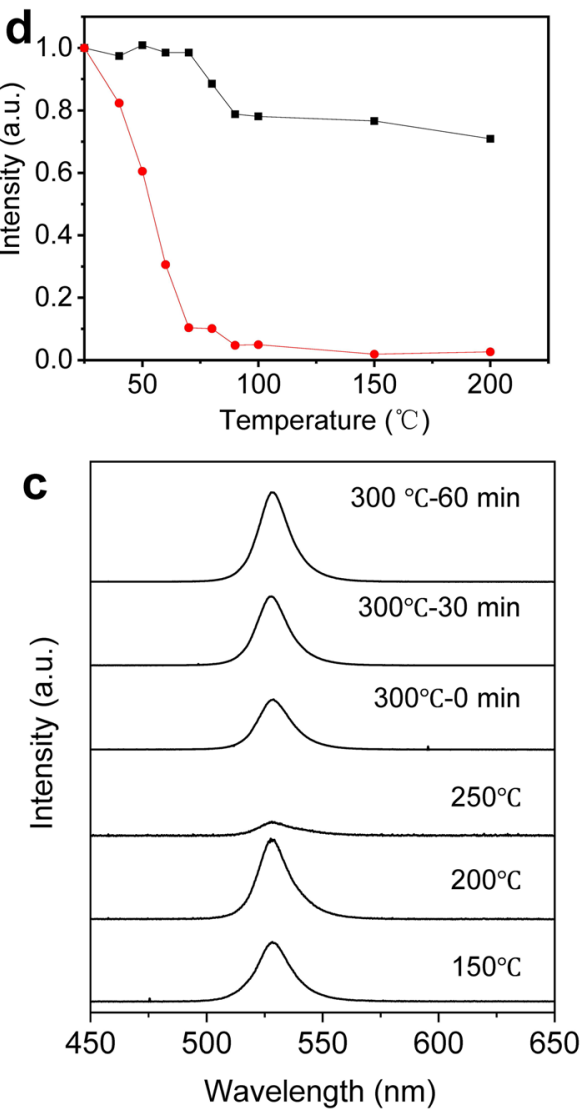

Fig. 3 Fluorescence of $\mathbf{C s}_{\mathbf{P b B r}}-\mathrm{NaYF}_{4}: \mathbf{Y b}, \mathbf{T m}$ hybrid nanocrystals. a Photographs showing different color fluorescence emitted from the heterostructured $\mathrm{CsPbBr}_{3}-\mathrm{NaYF}_{4}: \mathrm{Yb}, \mathrm{Tm}$ nanocrystals collected during the synthesis under different conditions (state $1,300{ }^{\circ} \mathrm{C}-0$ min, state $2,300{ }^{\circ} \mathrm{C}-$ $60 \mathrm{~min}$, both under $980 \mathrm{~nm}$ excitation, state $3,300^{\circ} \mathrm{C}-60 \mathrm{~min}$, under $365 \mathrm{~nm}$ excitation). b, c Fluorescence emission spectra of heterostructured $\mathrm{CsPbBr}_{3}-\mathrm{NaYF}_{4}: \mathrm{Yb}_{2} \mathrm{Tm}$ nanocrystals at different temperatures under $980 \mathrm{~nm}$ and $365 \mathrm{~nm}$ excitations, respectively. d Fluorescence intensity of $\mathrm{CsPbBr}_{3}$ nanocrystals (red) and heterostructured $\mathrm{CsPbBr}_{3}-\mathrm{NaYF}_{4}: \mathrm{Yb}, \mathrm{Tm}$ nanocrystals (black) collected at different temperatures under $365 \mathrm{~nm}$ excitation.

decreased due to the partial decomposition of the QDs. When the temperature was further increased to $300{ }^{\circ} \mathrm{C}$, the hybrid nanocrystals exhibited UV/blue upconversion fluorescence under $980 \mathrm{~nm}$ excitation (Fig. 3b), with emission peaks located at $292 \mathrm{~nm}$ $\left({ }^{1} \mathrm{I}_{6} \rightarrow{ }^{3} \mathrm{~F}_{4}\right), \quad 347 \mathrm{~nm} \quad\left({ }^{1} \mathrm{I}_{6} \rightarrow{ }^{3} \mathrm{~F}_{4}\right), \quad 362 \mathrm{~nm}\left({ }^{1} \mathrm{D}_{2} \rightarrow{ }^{3} \mathrm{H}_{6}\right), 450 \mathrm{~nm}$ $\left({ }^{1} \mathrm{D}_{2} \rightarrow{ }^{3} \mathrm{~F}_{4}\right)$, and $478 \mathrm{~nm}\left({ }^{1} \mathrm{G}_{4} \rightarrow{ }^{3} \mathrm{H}_{6}\right)$, and green fluorescence at $522 \mathrm{~nm}$ corresponding to the emission of $\mathrm{CsPbBr}_{3}$ QDs, suggesting a significant energy transfer from the $\mathrm{NaYF}_{4}: \mathrm{Yb}, \mathrm{Tm} \mathrm{UCNP}$ to $\mathrm{CsPBr}_{3}$ QDs and formation of hexagonal-phase $\mathrm{NaYF}_{4}: \mathrm{Yb}, \mathrm{Tm}$ UCNP. It has been reported that hexagonal-phase $\mathrm{NaYF}_{4}: \mathrm{Yb}, \mathrm{Tm}$ UCNP emits much stronger upconversion fluorescence as compared to its cubic phase $\mathrm{e}^{38-40}$. During the process of maintaining the temperature at $300{ }^{\circ} \mathrm{C}$ for 0 to $60 \mathrm{~min}$, the intensity of the green fluorescence emission peak increased, suggesting an increased energy transfer from the $\mathrm{NaYF}_{4}$ :Yb,Tm UCNP to CsPbBr 3 QDs. Meanwhile, at $300^{\circ} \mathrm{C}$, the hybrid nanocrystals emitted strong green fluorescence at $525 \mathrm{~nm}$ under $365 \mathrm{~nm}$ excitation which was corresponding to $\mathrm{CsPbBr}_{3}$ QDs (Fig. 3c). The absorption of the heterostructure composite of $\mathrm{CsPbBr}_{3}-\mathrm{NaYF}_{4}: \mathrm{Yb}, \mathrm{Tm}$ nanocrystals were around $510 \mathrm{~nm}$. The excitation spectrum showed that the heterostructure composite of $\mathrm{CsPbBr}_{3}-\mathrm{NaYF}_{4}: \mathrm{Yb}, \mathrm{Tm}$ nanocrystals exhibited the strongest peak at $475 \mathrm{~nm}$ monitored at the emission wavelength of $525 \mathrm{~nm}$, which is in good agreement with the result from the UV-vis absorption spectrum (Supplementary Fig. 13). During the process of nanocrystals formation and growth, the heterostructured nanocrystal at $250^{\circ} \mathrm{C}$ was composed of cubicphase UCNPs and cubic-phase $\mathrm{CsPbBr}_{3}$. When the temperature increased to $300^{\circ} \mathrm{C}$ and incubated for $60 \mathrm{~min}$, the cubic-phase
UCNPs changes to the hexagonal phase and resulted in the heterostructured nanocrystals of the hexagonal-phase UCNPs and cubic-phase $\mathrm{CsPBBr}_{3}$ formation. The PLQY of these heterostructured nanocrystals under excitation at $980 \mathrm{~nm}$ were as follows: $150{ }^{\circ} \mathrm{C}(0 \%), 200{ }^{\circ} \mathrm{C}(0 \%), 250{ }^{\circ} \mathrm{C}(0.02 \%), 300{ }^{\circ} \mathrm{C}-0 \min (0.15 \%)$, and $300^{\circ} \mathrm{C}-60 \mathrm{~min}(0.25 \%)$ (Supplementary Table 3). Similarly, the PLQY of these heterostructured nanocrystals increased from $0.02 \%$ to $0.139 \%$ under the $980 \mathrm{~nm}$ excitation. This PLQY increase was a result of the $\mathrm{NaYF}_{4}$ phase transition from cubic to hexagonal. The hexagonal-phase $\mathrm{NaYF}_{4}$ has a much higher fluorescence efficiency as compared to its cubic phase. The PLQY of these heterostructured nanocrystals under $365 \mathrm{~nm}$ excitation were as follows: $150{ }^{\circ} \mathrm{C}(53 \%), 200^{\circ} \mathrm{C}(35 \%), 250^{\circ} \mathrm{C}(12 \%), 300{ }^{\circ} \mathrm{C}-0 \min (23 \%)$, and $300^{\circ} \mathrm{C}-60 \mathrm{~min}(21 \%)$ (Supplementary Table 3). Under the excitation of $365 \mathrm{~nm}$, the peak position of heterostructured nanocrystals was $525 \mathrm{~nm}$. The PLQY increased from $12 \%$ to $23 \%$ during the heterostructured nanocrystal phase-transition process. The fluorescence quantum efficiency of the conventional $\mathrm{CsPbBr}$ nanocrystals was $65 \%$, and fluorescence quenching occurred after $\mathrm{CsPbBr}_{3}$ nanocrystals was kept at $300{ }^{\circ} \mathrm{C}$ for $60 \mathrm{~min}$ (Supplementary Table 3 and Supplementary Table 4). On the other hand, the PLQY of the perovskite within the heterostructured nanocrystals excited by $365 \mathrm{~nm}$ was about $21 \%$ after being kept at $300{ }^{\circ} \mathrm{C}$ for $60 \mathrm{~min}$ far higher than that of the conventional $\mathrm{CsPbBr}_{3}$ nanocrystals at $300^{\circ} \mathrm{C}$ for $60 \mathrm{~min}$ (Supplementary Table 4). The conventional $\mathrm{CsPbBr}_{3}$ nanocrystals were kept at $300{ }^{\circ} \mathrm{C}$ for $60 \mathrm{~min}$, resulting in very small-sized particles and very weak fluorescence (Supplementary Fig. 4). This is because the conventional CsPbBr 3 
nanocrystals shrank in size, dissolved, and their crystal structure was destroyed at $300^{\circ} \mathrm{C}$ after $60 \mathrm{~min}$. The heterojunctured nanocrystals have strong fluorescence at the $525 \mathrm{~nm}$ peak under $365 \mathrm{~nm}$ excitation, which fully indicated that the cubic-phase and hexagonal-phase UCNP have an obvious protective effect on $\mathrm{CsPbBr}$ nanocrystals at high temperature. The hybrid nanocrystals were reheated reheated to different temperatures of $25^{\circ} \mathrm{C}, 40{ }^{\circ} \mathrm{C}$, $50^{\circ} \mathrm{C}, 60^{\circ} \mathrm{C}, 70^{\circ} \mathrm{C}, 80^{\circ} \mathrm{C}, 90^{\circ} \mathrm{C}, 100^{\circ} \mathrm{C}, 150^{\circ} \mathrm{C}$, and $200^{\circ} \mathrm{C}$, and compared to pure $\mathrm{CsPbBr}_{3}$ perovskite QDs. When the temperature was increased to $200{ }^{\circ} \mathrm{C}$, the intensity of $\mathrm{CsPbBr}_{3}$ QDs quickly reduced to $2 \%$ while the intensity of the hybrid nanocrystals dropped to $71 \%$ only, showing the protection of the $\mathrm{CsPBr}_{3}$ QDs by the UCNP at high temperature (Fig. 3d and Supplementary Fig. 14). Relative fluorescence intensity of the heterostructured $\mathrm{CsPbBr} \mathrm{PaYF}_{3}: \mathrm{Na}_{4} \mathrm{Tm}$ hybrid nanocrystals still maintained around $90 \%$ during the heating process under $980 \mathrm{~nm}$ excitation (Supplementary Fig. 15). The hybrid nanocrystals maintained the luminescent properties of both perovskite QDs and UCNP and improved the stability of perovskite QDs at high temperatures.

Exploration of the energy-transfer mechanism. The Förster resonance energy transfer (FRET) and the emission reabsorption (ERA) were the two main energy-transfer processes. The changes in fluorescence lifetime are directly associated with FRET, but not with ERA. Efficient FRET between $\mathrm{NaYF}_{4}: \mathrm{Yb}$,Tm donors and $\mathrm{CsPbBr}{ }_{3}$ acceptors will only take place at short distances. Indeed, the fluorescence average lifetime reduction of the blue emission at $478 \mathrm{~nm}$ from $0.66 \mathrm{~ms}$ of the $\mathrm{NaYF}_{4}: 30 \% \mathrm{Yb}, 0.5 \% \mathrm{Tm}$ nanocrystals to $0.29 \mathrm{~ms}$ of the $\mathrm{CsPbBr}_{3}-\mathrm{NaYF}_{4}: \mathrm{Yb}, \mathrm{Tm}$ nanocrystals (Supplementary Fig. 16 and Supplementary Table 5) suggested that the energy transfer from $\mathrm{NaYF}_{4}: \mathrm{Yb}, \mathrm{Tm}$ to $\mathrm{CsPbBr}_{3}$ in the heterostructure follows a typical FRET process ${ }^{27,41}$. The FRET efficiency can be calculated with the equation Eff $=1-\tau_{D-A} / \tau_{D}$, where Eff is the energy transfer efficiency, $\tau_{D-A}$ is the effective lifetime of a donor conjugated with an acceptor, and $\tau_{D}$ is the effective lifetime of a donor in the absence of an acceptor. The FRET efficiency of the $\mathrm{CsPbBr}_{3}-\mathrm{NaYF}_{4}: \mathrm{Yb}, \mathrm{Tm}$ nanocrystals calculated was $56 \%$, which justifies our design for an efficient energy transport strategy. The fluorescence lifetime of the mixed $\mathrm{CsPbBr}_{3}$ and $\mathrm{NaYF}_{4}$ : $\mathrm{Yb}, \mathrm{Tm}$ is $0.59 \mathrm{~ms}$, which only reduces $0.07 \mathrm{~ms}$ compared with the $\mathrm{NaYF}_{4}: 30 \% \mathrm{Yb}, 0.5 \% \mathrm{Tm}$ NPs fluorescence lifetime of $0.66 \mathrm{~ms}$, and the efficiency of FRET is calculated to be $11 \%$, far lower than the energy transfer efficiency of FRET in the heterogeneous junction (Supplementary Figs. 16, 17 and Supplementary Tables 5, 6). Therefore, the energy transfer process of the mixed $\mathrm{CsPbBr}_{3}$ and $\mathrm{NaYF}_{4}: \mathrm{Yb}, \mathrm{Tm}$ is mainly EAU, which is different from that of FRET in heterostructured $\mathrm{Cs} \mathrm{PbBr}_{3}-\mathrm{NaYF}_{4}: \mathrm{Yb}, \mathrm{Tm}$ hybrid nanocrystals. In addition, the fluorescence lifetime of the perovskites has increased from $18 \mathrm{~ns}$ to $0.37 \mathrm{~ms}$ (Supplementary Fig. 18 and Supplementary Table 7).

By changing the number of perovskites, we have changed the ratio between the perovskite and UCNP in the heterostructured nanocrystals, and obtained 0.2 -fold and fivefold $\mathrm{CsPbBr}_{3}-\mathrm{NaYF}_{4}$ : $\mathrm{Yb}, \mathrm{Tm}$ nanocrystals. The fluorescence lifetime of the onefold heterostructured nanocrystal is $0.29 \mathrm{~ms}$ (Supplementary Fig. 19 and Supplementary Table 8). The fluorescence lifetime of the $0.2-$ fold heterostructured nanocrystal increased to $0.49 \mathrm{~ms}$, while that of the fivefold heterostructured nanocrystal decreased to $0.25 \mathrm{~ms}$ (Supplementary Table 8). As compared to the FRET efficiency of the onefold heterostructured nanocrystal, 56\%, the FRET efficiency of the 0.2-fold heterostructured nanocrystal was reduced to $25.8 \%$. On the other hand, the FRET efficiency of the fivefold heterostructured nanocrystal increased to $62.1 \%$ (Supplementary Table 9). Therefore, it shows that the decrease in the perovskite/UCNP ratio resulted in increased fluorescence lifetime and decreased FRET efficiency. Compared to the fluorescence spectra of pure UCNP under $980 \mathrm{~nm}$ excitation, the absorption of the fluorescence emitted from UCNP increases with the increase of the perovskite amount (Supplementary Fig. 20).

Regulation of optical properties. The heterojunction nanocrystals synthesized by us could undergo anion exchange with $\mathrm{Cl}^{-}$and $\mathrm{I}^{-}$to control the energy transfer and luminescence performance. Under the $980 \mathrm{~nm}$ excitation, the $525 \mathrm{~nm}$ fluorescence peak emitted by the perovskites within the heterogeneous crystals was shifted to $578 \mathrm{~nm}$ after the addition of $\mathrm{I}^{-}$. On the other hand, this same peak was shifted to $478 \mathrm{~nm}$ after the addition of $\mathrm{Cl}^{-}$(Supplementary Fig. 21A). During the anion exchange in $\mathrm{Cs} \mathrm{PbBr}_{3}$ nanocrystals with the introduction of $\mathrm{I}^{-}$into the heterogeneous crystal, and the fluorescence lifetime of $\mathrm{CsPbBr}_{3}$ nanocrystals in the heterojunction became longer. However, the introduction of $\mathrm{Cl}^{-}$into the heterojunction shortened the fluorescence lifetime of $\mathrm{CsPbBr}{ }_{3}$ nanocrystals in the heterogeneous crystal ${ }^{42}$, thus affecting the energy transfer efficiency. Under the $365 \mathrm{~nm}$ excitation, the $525 \mathrm{~nm}$ fluorescence peak emitted from the heterogeneous crystal was blue shifted to $479 \mathrm{~nm}$ and red shifted to $578 \mathrm{~nm}$, respectively (Supplementary Fig. 21B). Therefore, this heterojunction nanocrystal structure was able to regulate the energytransfer process and optical properties from $\mathrm{NaYF}_{4}: \mathrm{Yb}, \mathrm{Tm}$ to $\mathrm{CsPbBr}_{3}$ nanocrystals via anion exchange. Compared with pure UCNPs, heterogeneous crystals can not only regulate their optical properties through anion exchange but also change the composition of $\mathrm{CsPbX}_{3}$ nanocrystals in heterogeneous crystals. With the ratios of perovskites to UCNPs kept unchanged and only the perovskite composition was changed, we have obtained the heterostructured $\mathrm{CsPbBr} / \mathrm{Cl}_{1}-\mathrm{NaYF}_{4}: \mathrm{Yb}, \mathrm{Tm}$ nanocrystals and the heterostructured $\mathrm{CsPbBr}_{2} / \mathrm{I}_{1}-\mathrm{NaYF}_{4}: \mathrm{Yb}, \mathrm{Tm}$ nanocrystals. The size of the heterostructured $\mathrm{CsPbBr}_{2} / \mathrm{Cl}_{1}-\mathrm{NaYF}_{4}: \mathrm{Yb}$, Tm and $\mathrm{CsPbBr} /$ $\mathrm{I}_{1}-\mathrm{NaYF}_{4}: \mathrm{Yb}, \mathrm{Tm}$ nanocrystals were $42.3 \mathrm{~nm}$ and $39.6 \mathrm{~nm}$, respectively (Supplementary Fig. 24A, B). The irregular small particles of perovskite in the heterostructured nanocrystals were also observed. According to the fluorescence spectrum under the excitation of $980 \mathrm{~nm}$ (Supplementary Fig. 24C, D), the emission peak of the perovskites in the heterostructured $\mathrm{CsPbBr} / \mathrm{Cl}_{1}$ $\mathrm{NaYF}_{4}: \mathrm{Yb}_{\mathrm{T}} \mathrm{Tm}$ nanocrystals was shifted left to $477 \mathrm{~nm}$, while the emission peak of the perovskites in the heterostructured $\mathrm{CsPbBr}_{2} /$ $\mathrm{I}_{1}-\mathrm{NaYF}_{4}: \mathrm{Yb}, \mathrm{Tm}$ nanocrystals was shifted right to $542 \mathrm{~nm}$. Under $365 \mathrm{~nm}$ excitation, the fluorescence peaks of the heterostructured $\mathrm{CsPbBr} 2 / \mathrm{Cl}_{1}-\mathrm{NaYF}_{4}: \mathrm{Yb}, \mathrm{Tm}$ and $\mathrm{CsPbBr}_{2} / \mathrm{I}_{1}-\mathrm{NaYF}_{4}: \mathrm{Yb}, \mathrm{Tm}$ nanocrystals were $478 \mathrm{~nm}$ and $542 \mathrm{~nm}$ (Supplementary Fig. 24E, F), respectively. These peaks matched with the upconversion fluorescence peaks of $\mathrm{CsPbX}_{3}$ in the heterostructured nanocrystals which indicated that the $\mathrm{NaYF}_{4}: \mathrm{Yb}, \mathrm{Tm}$ has a protective effect on the structure of perovskite at high temperature. The fluorescence lifetimes of the heterostructured $\mathrm{CsPbBr}_{2} / \mathrm{Cl}_{1}-\mathrm{NaYF}_{4}: \mathrm{Yb}, \mathrm{Tm}$ and $\mathrm{CsPbBr} 2 / \mathrm{I}_{1}-\mathrm{NaYF}_{4}: \mathrm{Yb}, \mathrm{Tm}$ nanocrystals at the $478 \mathrm{~nm}$ peak were $0.23 \mathrm{~ms}$ and $0.48 \mathrm{~ms}$, respectively (Supplementary Fig. 24G-H and Supplementary Table 10). Therefore, we have shown that our synthesis strategy is compatible to synthesize heterogeneous junctions composed of different types of UCNPs and perovskites. If the aforementioned three conditions were met, different types of heterogeneous junction products such as PbS-UCNPs, CdSUCNPs can be obtained.

Phase transition. At $250^{\circ} \mathrm{C}$, the heterojunction nanocrystals mainly contained cubic-phase $\mathrm{CsPbBr} 3$ crystals and cubic-phase $\mathrm{NaYF}_{4}: \mathrm{Yb}$, Tm crystals according to the standard data of JCPDS\# 00-054-0752 and JCPDS\# 00-016-0334 (Supplementary Fig. 25). The $2 \theta$ of the $\{100\}$ crystal plane of the cubic-phase $\mathrm{CsPbBr}_{3}$ crystals has increased 

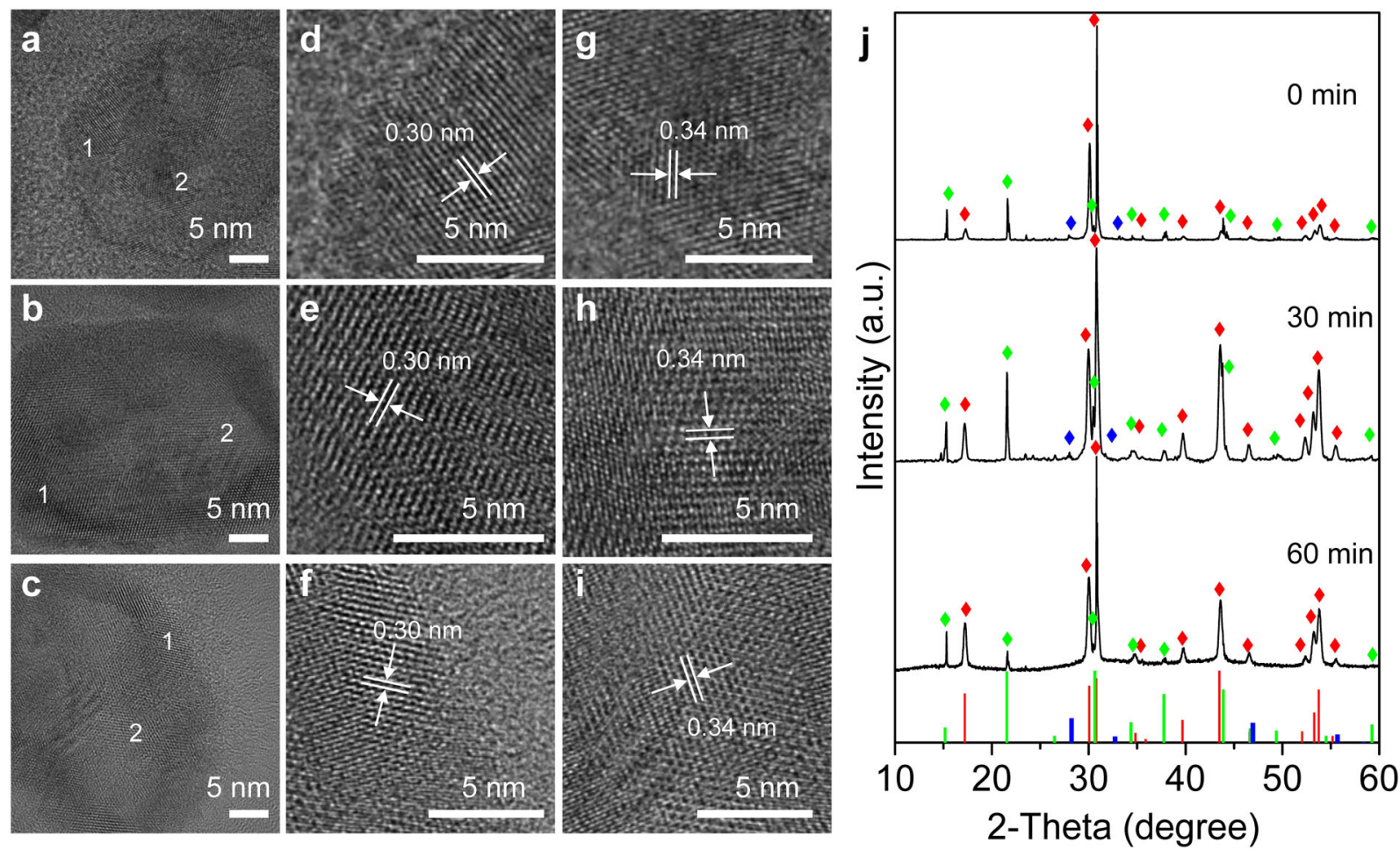

Fig. 4 Structural analysis of $\mathbf{C s P b B r}_{3}-\mathrm{NaYF}_{\mathbf{4}}: \mathbf{Y b}, \mathbf{T m}$ hybrid nanocrystals. HRTEM images of heterostructured $\mathrm{CsPbBr}_{3}-\mathrm{NaYF}_{4}: \mathrm{Yb}_{1}, \mathrm{Tm}_{\mathrm{m}}$ nanocrystals collected during the synthesis after heated at $300^{\circ} \mathrm{C}$ for different time: $\mathbf{a} 0 \mathrm{~min}, \mathbf{b} 30 \mathrm{~min}, \mathbf{c} 60 \mathrm{~min}$. $\mathbf{d}$-f Enlarged images of region 1 in $\mathbf{a}$, $\mathbf{b}$, and c, respectively. $\mathbf{g}$-i Enlarged images of region 2 in $\mathbf{a}, \mathbf{b}$, and $\mathbf{c}$, respectively. $\mathbf{j}$ X-ray diffraction (XRD) patterns of the three samples. Hexagonal NaYF 4 , red color (JCPDF\#00-016-0334), cubic NaYF 4 , blue color (JCPDF \#01-077-2042), cubic CsPbBr 3 , green color (JCPDF \#00-054-0752).

from $15.18^{\circ}$ to $15.3^{\circ}$, and the lattice spacing has decreased. On the other hand, the $2 \theta$ of the $\{100\}$ crystal plane of the cubic-phase $\mathrm{NaYF}_{4}: \mathrm{Yb}, \mathrm{Tm}$ crystals has decreased from $28.2^{\circ}$ to $27.8^{\circ}$, which further indicated that the lattice strain was generated by the heterojunction nanocrystals at $250^{\circ} \mathrm{C}$. In order to understand the phase transition during the process of maintaining the temperature at $300^{\circ}$ $\mathrm{C}$ for 0 to $60 \mathrm{~min}$, lattice spacing and XRD measurements for the above samples were performed. In this process, as seen in Fig. $4 \mathrm{a}-\mathrm{i}$, the lattice distance on the surface of the hybrid nanocrystals was 0.3 $\mathrm{nm}$ in accordance with the $\{110\}$ lattice spacing of hexagonal-phase $\mathrm{NaYF}_{4}$ UCNP (JCPDS: 00-016-0334), while the lattice distance in the middle was $0.34 \mathrm{~nm}$ corresponding to the $\{111\}$ lattice spacing of cubic-phase $\mathrm{CsPbBr}_{3}$ QDs (JCPDS: 00-054-0752). The highresolution TEM images confirmed that the two crystals were grown together and well combined which is very important to ensure a highly efficient energy transfer between them when excited at 980 $\mathrm{nm}$. At $300^{\circ} \mathrm{C}, \mathrm{XRD}$ results in Fig. $4 \mathrm{j}$ showed that the nanocrystals mainly contained cubic-phase $\mathrm{CsPbBr}_{3}$ crystals and hexagonal-phase $\mathrm{NaYF}_{4}$ crystals, according to the standard data of JCPDS\# 00-0540752 and JCPDS\# 00-016-0334. Very weak peaks of cubic-phase $\mathrm{NaYF}_{4}$ crystals (JCPDS: 01-077-2042) were also observed. With the extension of the thermal insulation time, the cubic-phase $\mathrm{NaYF}_{4}$ crystals transformed to hexagonal-phase $\mathrm{NaYF}_{4}$ crystals and finally disappeared, resulting in an increase in the relative proportion of hexagonal $\mathrm{NaYF}_{4}$ crystals (Supplementary Fig. 26), so only cubicphase $\mathrm{CsPbBr}_{3}$ crystals and hexagonal-phase $\mathrm{NaYF}_{4}$ crystals coexisted in the hybrid nanocrystals. The process of phase transition led to the formation of crystal boundary in the nanocrystal structure, which was confirmed with HRTEM results. When cubic-phase $\mathrm{NaYF}_{4}$ crystals transformed to the hexagonal phase with high fluorescence efficiency, upconversion fluorescence was enhanced, which was also consistent with the results of fluorescence measurement.
Stability study. The stability in a mixture solution of cyclohexane and ethanol with a ratio of 9:1 or 1:1 has significantly improved as compared to the conventional $\mathrm{CsPbBr}_{3}$ nanocrystals. We have studied the stability of heterostructure composite of $\mathrm{CsPBr}_{3}-$ $\mathrm{NaYF}_{4}: \mathrm{Yb}, \mathrm{Tm}$ nanocrystals in a mixture solution of cyclohexane and ethanol with a ratio of 9:1 (Fig. 5a and Supplementary Fig. 27) also. The relative fluorescence intensity of the $\mathrm{CsPbBr}$ nanocrystals decreased to $12 \%$ at $10 \mathrm{~min}$ and $5 \%$ at $120 \mathrm{~min}$ in the mixture solution. On the other hand, the heterostructure composite of $\mathrm{CsPbBr}_{3}-\mathrm{NaYF}_{4}: \mathrm{Yb}, \mathrm{Tm}$ nanocrystals has managed to maintain a relative fluorescence intensity of $93 \%$ at $10 \mathrm{~min}$ and $85 \%$ at $120 \mathrm{~min}$. This result suggests good stability in a mixture of cyclohexane and ethanol with a ratio of 9:1. Furthermore, the relative fluorescence intensity of the $\mathrm{CsPbBr}_{3}$ nanocrystals quickly decreased to $10 \%$ at $1 \mathrm{~min}$ and $5 \%$ at $120 \mathrm{~min}$ in a mixture of cyclohexane and ethanol with a ratio of $1: 1$ (Fig. 5b and Supplementary Fig. 27), whereas the heterostructure composite of $\mathrm{CsPbBr}_{3}-\mathrm{NaYF}_{4}: \mathrm{Yb}, \mathrm{Tm}$ nanocrystals has maintained a relative fluorescence intensity of $95 \%$ at $1 \mathrm{~min}$ and slowly decrease to $80 \%$ after $2 \mathrm{~h}$. This result suggests excellent fluorescence stability in a mixture of cyclohexane and ethanol with a ratio of 1:1. The stability of the heterostructure composite of $\mathrm{CsPbBr}_{3}-\mathrm{NaYF}_{4}: \mathrm{Yb}, \mathrm{Tm}$ nanocrystals in water was still less than ideal. As shown in Fig. 5c, the relative fluorescence intensity of $\mathrm{CsPbBr}_{3}$ nanocrystals in water solution has decreased to $<1 \%$ after $30 \mathrm{~s}$, while the relative fluorescence intensity of the heterostructure composite of $\mathrm{CsPbBr}{ }_{3}-\mathrm{NaYF}_{4}: \mathrm{Yb}, \mathrm{Tm}$ nanocrystals was able to remain at $46 \%$ in water solution (Supplementary Fig. 28). Even though the relative fluorescence intensity decreased to about $4 \%$ in $5 \mathrm{~min}$ eventually, the stability of these heterostructured nanocrystals in the water has shown slight improvement as compared to the conventional $\mathrm{CsPbBr}_{3}$ nanocrystals. From the results of solvent stability experiments, it can be inferred that there were bare 

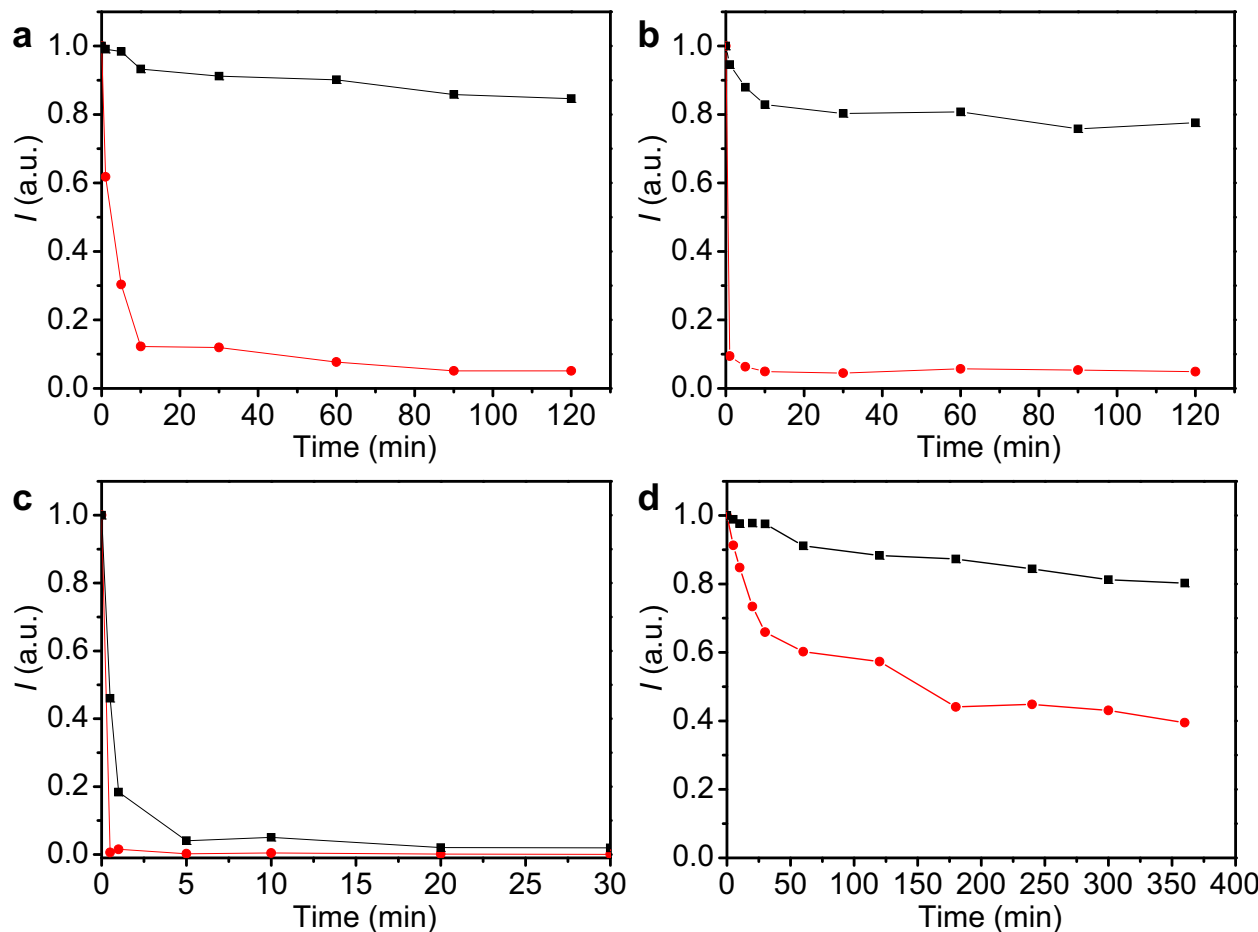

Fig. $\mathbf{5}$ Stability analysis of $\mathbf{C s}_{\mathbf{S b B r}} \mathbf{-}-\mathbf{N a Y F}_{\mathbf{4}}: \mathbf{Y b}, \mathbf{T m}$ hybrid nanocrystals. $\mathrm{PL}$ intensity test was used to monitor the stabilities of $\mathrm{CsPbBr}_{3}($ red) and the heterostructure composite of $\mathrm{CsPbBr}_{3}-\mathrm{NaYF}_{4}: \mathrm{Yb}, \mathrm{Tm}$ nanocrystals (black) in cyclohexane and ethanol ( $\left.\mathrm{v} / \mathrm{v}=9: 1\right)$ mixed solvent (a), cyclohexane and ethanol $(v / v=1: 1)$ mixed solvent (b), water solvent (c), and continuous ultraviolet light irradiation (d) under $365 \mathrm{~nm}$ excitation.

perovskite crystals on the heterogeneous crystal surface that were not completely covered by $\mathrm{NaYF}_{4}: \mathrm{Yb}, \mathrm{Tm}$ nanocrystals. Upon contact with the water molecules, the water molecules infiltrated into the heterogeneous crystal structure along with the perovskite found on the crystal surface. Thus, the perovskite crystal structure in the heterogeneous junction was destroyed and reduced the fluorescence significantly. In addition, we have studied light stability. Under continuous ultraviolet light, the $\mathrm{CsPbr}_{3}$ nanocrystals only have a $40 \%$ relative fluorescence intensity after 360 min, while heterostructure composite of $\mathrm{CsPbBr}_{3}-\mathrm{NaYF}_{4}: \mathrm{Yb}, \mathrm{Tm}$ nanocrystals maintained an $80 \%$ fluorescence intensity (Fig. $5 \mathrm{~d}$ and Supplementary Fig. 29). This result suggests that the heterostructured nanocrystals have good light stability.

\section{Discussion}

In summary, heterostructured $\mathrm{CsPbBr}_{3}-\mathrm{NaYF}_{4}: \mathrm{Yb}, \mathrm{Tm}$ nanocrystals were synthesized in one-pot with cubic-phase $\mathrm{CsPbBr}$ QDs embedded in hexagonal-phase $\mathrm{NaYF}_{4}: \mathrm{Yb}, \mathrm{Tm}$ UCNP to form a structure of watermelon with multiple seeds, using cubic-phase $\mathrm{NaYF}_{4}: \mathrm{Yb}, \mathrm{Tm}$ UCNP as an intermediate transition phase. Different phase crystals can not grow on each other epitaxially to form a heterostructure due to unmatched crystal structure and lattice. Synthesizing heterostructured nanocrystals with two or more different crystal phases remains a challenge. We have successfully demonstrated that cubic-phase perovskite QDs and hexagonal-phase UCNP could be combined into a single nanocrystal by introducing an intermediate transition phase into the synthesis. Cubic-phase UCNP was grown on cubic-phase perovskite QDs to form single nanocrystals, followed by a phase transition from cubic-phase UCNP to hexagonal-phase UCNP by heating to a higher temperature, to obtain monodispersed and heterostructured perovskite-UCNP nanocrystals with multiple cubic-phase perovskite QDs embedded in hexagonal-phase UCNP. Going beyond this, a generic strategy has been developed to synthesize heterostructured nanocrystals with different phases based on phase transition and this could be readily applied to many other materials.

\section{Methods}

Chemicals and materials. Cesium carbonate $\left(\mathrm{Cs}_{2} \mathrm{CO}_{3}, 99.9 \%\right)$, lead bromide $\left(\mathrm{PbBr}_{2}, 99.9 \%\right)$, lead chloride $\left(\mathrm{PbCl}_{2}, 99.9 \%\right)$, lead iodide $\left(\mathrm{PbI}_{2}, 99.9 \%\right)$, yttrium acetate $\left(\left(\mathrm{CH}_{3} \mathrm{CO}_{2}\right)_{3} \mathrm{Y} \cdot \mathrm{xH}_{2} \mathrm{O}, 99.9 \%\right)$, ytterbium acetate $\left(\left(\mathrm{CH}_{3} \mathrm{CO}_{2}\right)_{3} \mathrm{Yb} \cdot 4 \mathrm{H}_{2} \mathrm{O}\right.$, $99.9 \%)$, thulium(III) acetate $\left(\left(\mathrm{CH}_{3} \mathrm{CO}_{2}\right)_{3} \mathrm{Tm} \cdot \mathrm{xH}_{2} \mathrm{O}, 99.9 \%\right)$, sodium hydroxide $(\mathrm{NaOH}, 99 \%)$, ammonium fluoride $\left(\mathrm{NH}_{4} \mathrm{~F}, 98 \%\right)$, octadecene (ODE, 95\%), oleic acid (OA, 90\%), oleylamine (OAm, 98\%), oleylamine chloride (OAmCl, 99\%), oleylamine iodide (OAmI, 99\%), cyclohexane (99.9\%), and toluene (99.9\%) were purchased from Sigma-Aldrich and used as received without further purification.

Synthesis of $\mathrm{CsPbBr}_{3}$ perovskite nanocrystals. Cs-oleate was synthesized by reacting $\mathrm{Cs}_{2} \mathrm{CO}_{3}(0.2 \mathrm{~g})$ with $\mathrm{OA}(0.6 \mathrm{~mL})$ in octadecene $(7.5 \mathrm{~mL})$ and pre-heated to $120^{\circ} \mathrm{C}$ before injection. $\mathrm{PbBr}_{2}(0.188 \mathrm{mmol})$ and $5 \mathrm{~mL}$ of ODE were loaded into a $100 \mathrm{~mL} \mathrm{3-neck} \mathrm{flask,} \mathrm{dried} \mathrm{under} \mathrm{vacuum} \mathrm{at} 120^{\circ} \mathrm{C}$ for $1 \mathrm{~h}$, and mixed with vacuum-dried $\mathrm{OAm}(0.5 \mathrm{~mL})$ and $\mathrm{OA}(0.5 \mathrm{~mL})$ under a $\mathrm{N}_{2}$ atmosphere. The temperature was raised to $150^{\circ} \mathrm{C}$, and $0.6 \mathrm{~mL}$ of Cs-oleate solution was rapidly injected. After $5 \mathrm{~s}$, the reaction mixture was cooled in an ice-water bath. Nanocrystals were precipitated by centrifugation at $12,000 \mathrm{rpm}$ and re-dispersed in $10 \mathrm{~mL}$ of cyclohexane. Other samples $\left(\mathrm{CsPbBr}_{2} \mathrm{Cl}_{1}\right.$ and $\left.\mathrm{CsPbBr}_{2} \mathrm{I}_{1}\right)$ with different ratios of $\mathrm{Br} / \mathrm{Cl}$ or $\mathrm{I}=2 / 1$ were synthesized by the same strategy. The other conditions for synthesis and purification remain the same.

Synthesis of heterostructured $\mathrm{CsPbBr}_{\mathbf{3}}-\mathrm{NaYF}_{\mathbf{4}}$ : $\mathbf{Y b}, \mathbf{T m}$ nanocrystals. First, $0.695 \mathrm{mmol} \mathrm{Y}\left(\mathrm{CH}_{3} \mathrm{CO}_{2}\right)_{3}, 0.30 \mathrm{mmol} \mathrm{Yb}\left(\mathrm{CH}_{3} \mathrm{CO}_{2}\right)_{3}$, and $0.005 \mathrm{mmol} \mathrm{Tm}$ $\left(\mathrm{CH}_{3} \mathrm{CO}_{2}\right)_{3}$ were mixed with $6 \mathrm{~mL}$ of oleic acid and $15 \mathrm{~mL}$ of octadecene in a 50 -mL flask and heated to $150^{\circ} \mathrm{C}$. After cooled down to room temperature, $10 \mathrm{~mL}$ of methanol solution $\left(100 \mathrm{mg} \mathrm{NaOH}\right.$ and $\left.150 \mathrm{mg} \mathrm{NH}_{4} \mathrm{~F}\right)$ were slowly added into the flask, and the solution was stirred for $10 \mathrm{~min}$. The solution was subsequently heated to remove methanol and degassed at $120^{\circ} \mathrm{C}$ for $20 \mathrm{~min}$. In all, $1 \mathrm{~mL}$ of $\mathrm{CsPbBr}$ solution was hot-injected into the precursor solution and then heated to $300^{\circ} \mathrm{C}$ for $1 \mathrm{~h}$ under $\mathrm{N}_{2}$ environment. The product was washed twice with cyclohexane by centrifugation for $10 \mathrm{~min}$ and dispersed in $20 \mathrm{~mL}$ of cyclohexane for further use. The ratio between $\mathrm{CsPbBr}_{3}$ and $\mathrm{NaYF}_{4}$ : Yb,Tm nanocrystals could be adjusted.

Synthesis of heterostructured $\mathrm{CsPbBr}_{2} \mathrm{Cl}_{1}-\mathrm{NaYF}_{4}: \mathrm{Yb}, \mathrm{Tm}$ and heterostructured $\mathrm{CsPbBr}_{2} \mathrm{I}_{\mathbf{1}}-\mathrm{NaYF}_{\mathbf{4}}: \mathbf{Y b}, \mathbf{T m}$ nanocrystals. In total, $0.695 \mathrm{mmol}$ $\left(\mathrm{CH}_{3} \mathrm{CO}_{2}\right)_{3} \mathrm{Y}, 0.30 \mathrm{mmol}\left(\mathrm{CH}_{3} \mathrm{CO}_{2}\right)_{3} \mathrm{Yb}$, and $0.005 \mathrm{mmol}\left(\mathrm{CH}_{3} \mathrm{CO}_{2}\right)_{3} \mathrm{Tm}$ were 
mixed with $6 \mathrm{~mL}$ of oleic acid and $15 \mathrm{~mL}$ of octadecene in a $50-\mathrm{mL}$ flask and heated to $150{ }^{\circ} \mathrm{C}$. After cooled down to room temperature, $10 \mathrm{~mL}$ of methanol solution (100 $\mathrm{mg} \mathrm{NaOH}$ and $150 \mathrm{mg} \mathrm{NH}_{4} \mathrm{~F}$ ) was slowly added into the flask, and the solution was stirred for $10 \mathrm{~min}$. The solution was subsequently heated to remove methanol and degassed at $120^{\circ} \mathrm{C}$ for $20 \mathrm{~min}$. In all, $1 \mathrm{~mL}$ of $\mathrm{CsPbBr}_{2} \mathrm{I}_{1}$ or $\mathrm{CsPbBr}{ }_{2} \mathrm{I}_{1}$ solution was hot-injected into the precursor solution and then heated to $300{ }^{\circ} \mathrm{C}$ for $1 \mathrm{~h}$ under $\mathrm{N}_{2}$ environment. The product was washed twice with cyclohexane by centrifugation for $10 \mathrm{~min}$ and dispersed in $20 \mathrm{~mL}$ of cyclohexane for further use.

\section{Anion exchange of heterostructured $\mathrm{CsPbBr}_{3}-\mathrm{NaYF}_{4}: \mathrm{Yb}_{,} \mathrm{Tm}$ nanocrystals.} The anion-exchange reactions were performed in a $10-\mathrm{mL}$ glass bottle. The heterostructured $\mathrm{CsPbBr}_{3}-\mathrm{NaYF}_{4}$ : Yb,Tm nanocrystals $(5 \mathrm{~mL}, 0.05 \mathrm{~mol} / \mathrm{L})$ were used as the precursor. For anion exchange, $\mathrm{OAmI}$ or $\mathrm{OAmCl}(20 \mathrm{mg})$ was dissolved in cyclohexane $(20 \mathrm{~mL})$ as the anion source, and add $850 \mu \mathrm{L}$ of OAmI or $700 \mu \mathrm{L}$ of $\mathrm{OAmCl}$ solution into the heterostructured nanocrystals solution $(5 \mathrm{~mL})$ to achieve anion exchange. Anion exchange could be completed in a time period ranging from tens of seconds to a few minutes. After the reaction, the emission peaks of the solution were detected by a spectrofluorometer.

Characterization. TEM was performed on an FEI Tecnai G2 F20 electron microscope operating at $200 \mathrm{kV}$. Low-voltage high-resolution STEM measurement was carried out on a double-aberration-corrected $\mathrm{Titan}^{\mathrm{TM}}$ cubed G2 60-300 S/ TEM equipped with Super-XTM technology. The available point resolution is $\sim 0.1$ $\mathrm{nm}$ at an operating voltage of $60 \mathrm{kV}$. XRD was measured with a Bruker AXS D8 Xray diffractometer equipped with monochromatized $\mathrm{Cu} \mathrm{Ka}$ radiation $(\lambda=1.5418$ $\AA$ ). XPS was performed using an achromatic Al Ka source $(1486.6 \mathrm{eV})$ and a double-pass cylindrical mirror analyzer (ULVACPHI 5000 Versa Probe) (Japan). Heterostructured nanocrystals were dissolved in cyclohexane solution at a concentration of $0.05 \mathrm{~mol} / \mathrm{L}$, and the upconversion fluorescence spectrum, downconversion fluorescence spectrum, absorption spectrum, excitation spectrum, and fluorescence lifetime were tested and characterized. Ultraviolet and visible absorption (UV-vis) spectra were recorded with a Shimadzu UV-3600 plus spectrophotometer equipped with an integrating sphere under ambient conditions. Photoluminescence excitation and emission spectra and fluorescence decays were recorded on a FLS980 spectrometer (Edinburgh) equipped with both continuous xenon $(450 \mathrm{~W})$ and pulsed flash lamps. Upconversion fluorescence emission spectra were acquired under $980 \mathrm{~nm}$ excitation with a CW diode laser $\left(2 \mathrm{~W} / \mathrm{cm}^{2}\right)$. Measurement of absolute up- and down-conversion PLQY of nanocrystals was performed using a standard barium sulfate-coated integrating sphere (Edinburgh). The sample chamber was mounted to a FLS980 spectrophotometer. Lifetime was measured with a customized UV to mid-infrared steady-state and phosphorescence lifetime spectrometer (FSP920-C, Edinburgh) equipped with a digital oscilloscope (TDS3052B, Tektronix) and a tunable mid-band Optical Parametric Oscillator pulsed laser as the excitation source $(410-2400 \mathrm{~nm}, 10 \mathrm{~Hz}$, pulse width $\leq 5 \mathrm{~ns}$, Vibrant 355II, OPOTEK). Fluorescence decay was measured on a Nikon Ni-U Microfluorescence Lifetime system with a $375 \mathrm{~nm}$ picosecond laser and a timecorrelated single-photon counting system at room temperature.

\section{Data availability}

The data that support the findings of this study are available from the corresponding author upon reasonable request.

Received: 30 July 2020; Accepted: 8 December 2020; Published online: 11 January 2021

\section{References}

1. Jang, Y. et al. Interface control of electronic and optical properties in IV-VI and II-VI core/shell colloidal quantum dots: a review. Chem. Commun. 53, 1002-1024 (2017).

2. Wang, H. et al. Semiconductor heterojunction photocatalysts: design, construction, and photocatalytic performances. Chem. Soc. Rev. 43, 5234-5244 (2014).

3. Ekimov, A. I., Efros, A. L. \& Onushchenko, A. A. Quantum size effect in semiconductor microcrystals. Solid State Commun. 56, 921-924 (1985).

4. Owen, J. \& Brus, L. Chemical synthesis and luminescence applications of colloidal semiconductor quantum dots. J. Am. Chem. Soc. 139, 10939-10943 (2017).

5. Heath, R. J. Covalency in semiconductor quantum dots. Chem. Soc. Rev. 27, 65-71 (1998).

6. Liu, F. et al. Highly luminescent phase-stable $\mathrm{CsPb}_{3}$ perovskite quantum dots achieving near $100 \%$ absolute photoluminescence quantum yield. ACS Nano 11, 10373-10383 (2017).
7. Wu, J. et al. Efficient and stable thin-film luminescent solar concentrators enabled by near-infrared emission perovskite nanocrystals. Angew. Chem. Int. Ed. 59, 7738-7742 (2020).

8. Gonzalez-Carrero, S. et al. The luminescence of $\mathrm{CH}_{3} \mathrm{NH}_{3} \mathrm{PbBr}_{3}$ perovskite nanoparticles crests the summit and their photostability under wet conditions is enhanced. Small 12, 5245-5250 (2016).

9. Wang, Y. et al. Nonlinear absorption and low-threshold multiphoton pumped stimulated emission from all-inorganic perovskite nanocrystals. Nano Lett. 16, 448-453 (2016).

10. Nedelcu, G. et al. Fast anion-exchange in highly luminescent nanocrystals of cesium lead halide perovskites $\left(\mathrm{CsPb}_{3}, \mathrm{X}=\mathrm{Cl}, \mathrm{Br}, \mathrm{I}\right)$. Nano Lett. 15, 5635-5640 (2015)

11. Yakunin, S. et al. Low-threshold amplified spontaneous emission and lasing from colloidal nanocrystals of caesium lead halide perovskites. Nat. Сотти $\mathbf{6}$, 8056 (2015)

12. Oga, H., Saeki, A., Ogomi, Y., Hayase, S. \& Seki, S. Improved understanding of the electronic and energetic landscapes of perovskite solar cells: high local charge carrier mobility, reduced recombination, and extremely shallow traps. J. Am. Chem. Soc. 136, 13818-13825 (2014).

13. Stoumpos, C. C. \& Kanatzidis, M. G. The renaissance of halide perovskites and their evolution as emerging semiconductors. Acc. Chem. Res. 48, 2791-2802 (2015).

14. Green, M. A., Ho-Baillie, A. \& Snaith, H. J. The emergence of perovskite solar cells. Nat. Photonics 8, 506-514 (2014).

15. Mahalingam, V., Vetrone, F., Naccache, R., Speghini, A. \& Capobianco, J. A. Colloidal Tm3+/Yb3+-doped $\mathrm{LiYF}_{4}$ nanocrystals: multiple luminescence spanning the UV to NIR regions via low-energy excitation. Adv. Mater. 21, 4025-4028 (2009).

16. Zheng, W. et al. Lanthanide-doped upconversion nano-bioprobes: electronic structures, optical properties, and biodetection. Chem. Soc. Rev. 44, 1379-1415 (2015).

17. Zhou, B., Shi, B., Jin, D. \& Liu, X. Controlling upconversion nanocrystals for emerging applications. Nat. Nanotechnol. 10, 924-936 (2015).

18. Idris, N. M. et al. In vivo photodynamic therapy using upconversion nanoparticles as remote-controlled nanotransducers. Nat. Med. 18, 1580-1585 (2012).

19. Jalani, G. et al. Photocleavable hydrogel-coated upconverting nanoparticles: a multifunctional theranostic platform for NIR imaging and on-demand macromolecular delivery. J. Am. Chem. Soc. 138, 1078-1083 (2016).

20. Jayakumar, M. K. G., Idris, N. M. \& Zhang, Y. Remote activation of biomolecules in deep tissues using near-infrared-to-UV upconversion nanotransducers. Proc. Natl Acad. Sci. USA 109, 8483 (2012).

21. Tang, X. et al. Single halide perovskite/semiconductor core/shell quantum dots with ultrastability and nonblinking properties. Adv. Sci. 6, 1900412 (2019).

22. Zhang, $\mathrm{X}$. et al. $\mathrm{PbS}$ capped $\mathrm{CsPbI}_{3}$ nanocrystals for efficient and stable lightemitting devices using $\mathrm{p}-\mathrm{i}-\mathrm{n}$ structures. ACS central. Science 4, 1352-1359 (2018).

23. Li, Z.-J. et al. Photoelectrochemically active and environmentally stable $\mathrm{CsPbBr} / \mathrm{TiO}_{2}$ core/shell nanocrystals. Adv. Funct. Mater. 28, 1704288 (2018).

24. Ning, Z. et al. Quantum-dot-in-perovskite solids. Nature 523, 324-328 (2015)

25. Zhang, $\mathrm{X}$. et al. Heterostructural $\mathrm{CsPbX}_{3}-\mathrm{PbS}(\mathrm{X}=\mathrm{Cl}, \mathrm{Br}$, I) quantum dots with tunable Vis-NIR dual emission. J. Am. Chem. Soc. 142, 4464-4471 (2020).

26. Francés-Soriano, L. et al. Efficient cementing of $\mathrm{CH}_{3} \mathrm{NH}_{3} \mathrm{PbBr}_{3}$ nanoparticles to upconversion nanoparticles visualized by confocal microscopy. Adv. Funct. Mater. 26, 5131-5138 (2016).

27. Yang, B. et al. Solution-processable near-infrared-responsive composite of perovskite nanowires and photon-upconversion nanoparticles. Adv. Funct. Mater. 28, 1801782 (2018).

28. Zhong, Q. X. et al. One-pot synthesis of highly stable $\mathrm{CsPbBr}_{3} @ \mathrm{SiO}_{2}$ coreshell nanoparticles. Acs Nano 12, 8579-8587 (2018).

29. Zhang, F. et al. Uniform nanostructured arrays of sodium rare-earth fluorides for highly efficient multicolor upconversion luminescence. Angew. Chem. Int. Ed. 46, 7976-7979 (2007).

30. Protesescu, L. et al. Nanocrystals of cesium lead halide perovskites $(\mathrm{CsPbX}, \mathrm{X}$ $=\mathrm{Cl}, \mathrm{Br}$, and I): novel optoelectronic materials showing bright emission with wide color gamut. Nano Lett. 15, 3692-3696 (2015).

31. Li, Z., Zhang, Y. \& Jiang, S. Multicolor core/shell-structured upconversion fluorescent nanoparticles. Adv. Mater. 20, 4765-4769 (2008)

32. Zhao, M., Shi, Y., Dai, J. \& Lian, J. Ellipsometric study of the complex optical constants of a $\mathrm{CsPbBr}_{3}$ perovskite thin film. J. Mater. Chem. C. 6, 10450-10455 (2018).

33. Wei, Y. et al. Epitaxial Growth of $\mathrm{CsPb}_{3}(\mathrm{X}=\mathrm{Cl}, \mathrm{Br}, \mathrm{I})$ perovskite quantum dots via surface chemical conversion of $\mathrm{Cs}_{2} \mathrm{GeF}_{6}$ double perovskites: a novel strategy for the formation of leadless hybrid perovskite phosphors with enhanced stability. Adv. Mater. 31, 1807592 (2019). 
34. Roy, D. M. \& Roy, R. Controlled massively defective crystalline solutions with the fluorite structure. J. Electrochem. Soc. 111, 421 (1964).

35. Wang, H. C. et al. Mesoporous silica particles integrated with all-inorganic $\mathrm{Cs} \mathrm{PbBr}_{3}$ perovskite quantum-dot nanocomposites (MP-PQDs) with high stability and wide color gamut used for backlight display. Angew. Chem.-Int. Ed. 55, 7924-7929 (2016).

36. Yuan, $\mathrm{X}$. et al. Thermal degradation of luminescence in inorganic perovskite $\mathrm{CsPbBr}_{3}$ nanocrystals. Phys. Chem. Chem. Phys. 19, 8934-8940 (2017).

37. Mai, H.-X., Zhang, Y.-W., Sun, L.-D. \& Yan, C.-H. Size- and phase-controlled synthesis of monodisperse $\mathrm{NaYF}_{4}: \mathrm{Yb}$,Er nanocrystals from a unique delayed nucleation pathway monitored with upconversion spectroscopy. J. Phys. Chem. C. 111, 13730-13739 (2007).

38. Wei, Y., Lu, F., Zhang, X. \& Chen, D. Synthesis of oil-dispersible hexagonalphase and hexagonal-shaped $\mathrm{NaYF}_{4}: \mathrm{Yb}$,Er nanoplates. Chem. Mater. 18, 5733-5737 (2006).

39. Mai, H.-X. et al. High-quality sodium rare-earth fluoride nanocrystals: controlled synthesis and optical properties. J. Am. Chem. Soc. 128, 6426-6436 (2006).

40. Liu, C., Wang, H., Li, X. \& Chen, D. Monodisperse, size-tunable and highly efficient $\beta-\mathrm{NaYF}_{4}: \mathrm{Yb}, \mathrm{Er}(\mathrm{Tm})$ up-conversion luminescent nanospheres: controllable synthesis and their surface modifications. J. Mater. Chem. 19, 3546-3553 (2009).

41. Singldinger, A., Gramlich, M., Gruber, C., Lampe, C. \& Urban, A. S. Nonradiative energy transfer between thickness-controlled halide perovskite nanoplatelets. ACS Energy Lett. 5, 1380-1385 (2020).

42. Zheng, W. et al. Near-infrared-triggered photon upconversion tuning in allinorganic cesium lead halide perovskite quantum dots. Nat. Commu 9, 3462 (2018).

\section{Acknowledgements}

We acknowledge financial support from the Ministry of Education of Singapore (MOE) under its Tier3 and Tier1 programme (MOE 2016-T3-1-004, R-397-000-274-112, R-397000-270-114), National Medical Research Council (NMRC/OFIRG/17nov066, R-397000-317-213), and the National University of Singapore.

\section{Author contributions}

Y.Z. conceived and supervised the project. L.R. performed the studies. All authors participated in analyzing the results, preparing the figures, and writing the paper.

\section{Competing interests}

The authors declare no competing interests.

\section{Additional information}

Supplementary information is available for this paper at https://doi.org/10.1038/s41467020-20551-z.

Correspondence and requests for materials should be addressed to Y.Z.

Peer review information Nature Communications thanks Maria González-Béjar and the other, anonymous, reviewer(s) for their contribution to the peer review of this work.

Reprints and permission information is available at http://www.nature.com/reprints

Publisher's note Springer Nature remains neutral with regard to jurisdictional claims in published maps and institutional affiliations.

cc (i) Open Access This article is licensed under a Creative Commons Attribution 4.0 International License, which permits use, sharing, adaptation, distribution and reproduction in any medium or format, as long as you give appropriate credit to the original author(s) and the source, provide a link to the Creative Commons license, and indicate if changes were made. The images or other third party material in this article are included in the article's Creative Commons license, unless indicated otherwise in a credit line to the material. If material is not included in the article's Creative Commons license and your intended use is not permitted by statutory regulation or exceeds the permitted use, you will need to obtain permission directly from the copyright holder. To view a copy of this license, visit http://creativecommons.org/ licenses/by/4.0/.

(C) The Author(s) 2021 